\title{
Appendiceal cancer leading to intussusception detected incidentally during follow-up for Peutz-Jeghers syndrome
}

\author{
Kazuhiro Kurihara $^{1}$ (D) Takanori Suganuma $^{1}$ (D)
}

Received: 30 January 2020 / Accepted: 2 August 2020 / Published online: 9 October 2020

(c) The Author(s) 2020

\begin{abstract}
Peutz-Jeghers syndrome is an autosomal dominant disorder characterized by hamartomatous polyposis, pigmentation, and malignant tumors. We report a case of ileocecal carcinoma that was incidentally detected during follow-up for Peutz-Jeghers syndrome. A 39-year-old man with solitary Peutz-Jeghers syndrome had undergone three abdominal surgeries. He had been followed up via upper and lower gastrointestinal endoscopy and small intestinal endoscopy. In the endoscopic examination of the lower gastrointestinal tract, a $35 \mathrm{~mm}$ large, bumpy, elevated lesion was observed in the cecum. This lesion was not observed 9 months earlier during lower endoscopy. Biopsy of the specimen confirmed tubulovillous adenoma and carcinoma. This lesion was judged to be an indication for operation, and we performed ileocecectomy $+\mathrm{D} 3$ lymph node dissection. From the excised specimen, poorly differentiated carcinoma and adenoma components in contact with Peutz-Jeghers-type polyps in the appendix were recognized. A review of the computed tomography image obtained 2 years ago confirmed appendiceal swelling. We suspect that the ileocecal carcinoma in the appendix may have rapidly developed within the 9 months, and was incidentally detected on lower endoscopic examination during follow-up. For the prevention of appendicular tumorigenesis, prophylactic appendectomy may be considered in certain cases during follow-up for Peutz-Jeghers syndrome.
\end{abstract}

Keywords Case report $\cdot$ Peutz-jeghers syndrome $\cdot$ Ileocecal carcinoma $\cdot$ Peutz-jeghers-type polyps

\section{Introduction}

Peutz-Jeghers syndrome (PJS) is characterized by hamartomatous polyposis, pigmentation, autosomal dominant inheritance, and neoplastic transformation derived from Peutz-Jeghers polyposis [1]. We report a case of ileocecal carcinoma detected incidentally during follow-up for PJS.

\section{Case report}

\section{Chief complaints}

A 39-year-old man with PJS reported to our emergency room with watery diarrhea, vomiting, and abdominal distension for several days.

Takanori Suganuma

imh3913@imh.jp

1 Department of Gastroenterology, Iida Municipal Hospital, Iida, Nagano 395-8502, Japan

\section{History of presenting illness}

The patient reported that the symptoms of watery diarrhea, vomiting, and abdominal distension had appeared in the beginning of December 2017. When the patient visited a primary care doctor, the leukocyte count and C-reactive protein level were high. Cefmetazole ( $1 \mathrm{~g} /$ day) was administered for 5 days. However, the symptoms worsened, and the patient reported to our emergency room.

\section{History of past illness}

The patient had undergone laparotomy for small intestinal and gastric polyps at the age of 9 and 18 years, respectively. At the age of 33 years, he had undergone forward resection for sigmoid colon cancer: type 1 , pap + tub $1, \mathrm{f}$ stage I (pT2pN0cM0) (TNM classification, 8th edition) and had been followed up with upper and lower gastrointestinal endoscopy once a year since then. He had also undergone small intestinal polypectomy at the age of 34 years and endoscopic mucosal resection for colonic polyps at the age of 35 years, and for numerous polyps from 
the ascending colon to the rectum at the age of 37 years; at both instances, the polyps were Peutz-Jeghers-type hamartomas.

In February 2017, lower gastrointestinal endoscopy had been performed, confirming that there was no tumor in the ileocecal area (Fig. 1).

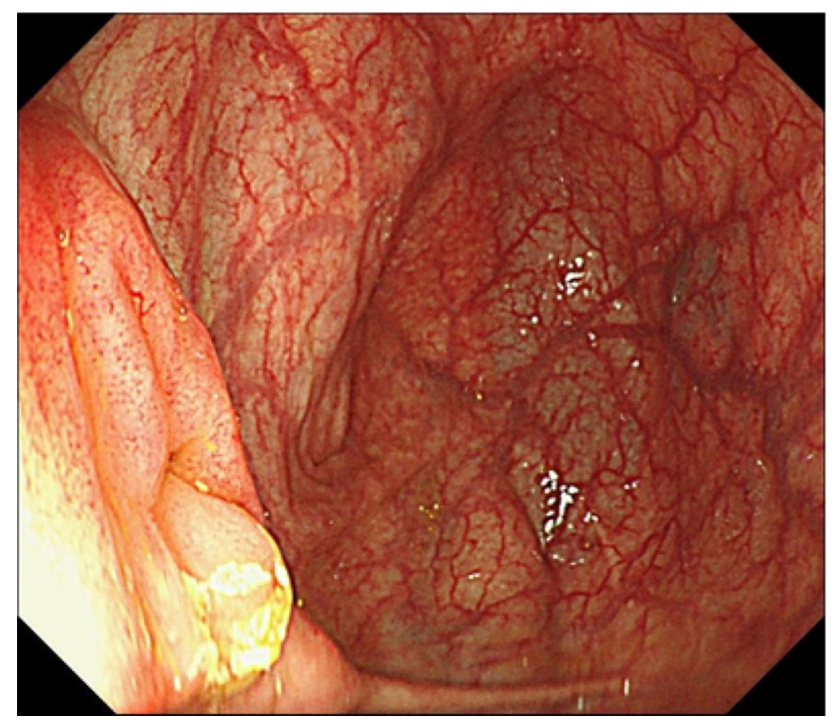

Fig. 1 Lower gastrointestinal endoscopy performed in February 2017

\section{Physical examination}

The patient's height was $153.6 \mathrm{~cm}$ and weight was $52.10 \mathrm{~kg}$. The physical examination further revealed a body temperature of $36.5{ }^{\circ} \mathrm{C}$, pulse of 100 beats $/ \mathrm{min}$, blood pressure of 125/77 $\mathrm{mmHg}$, and saturated oxygen of $97 \%$ at room air. The eyelid conjunctiva did not indicate anemia, and there was no yellowing of the bulbar conjunctiva. The patient was scarred because of the multiple surgeries. The epicardial region was distorted; however, no tenderness and rebound pain were observed. Tenderness at the McBurney point was evident along with a negative Murphy sign and diminished intestinal movement noise. There was brownish black pigmentation up to $5 \mathrm{~mm}$ in size on his face, lip, palm, and fingers.

\section{Imaging examinations}

The niveau sign and gas in the small intestine were noted on an abdominal plain radiograph (Fig. 2a, b). Moreover, thickening of the wall of the cecum and discontinuous dilated regions of the small intestine and colon were seen on abdominal computed tomography (CT) (Fig. 3a, b). Based on these findings, he was diagnosed with paralytic ileus and admitted to our hospital in December 2017. On the third day of hospitalization, we performed a lower

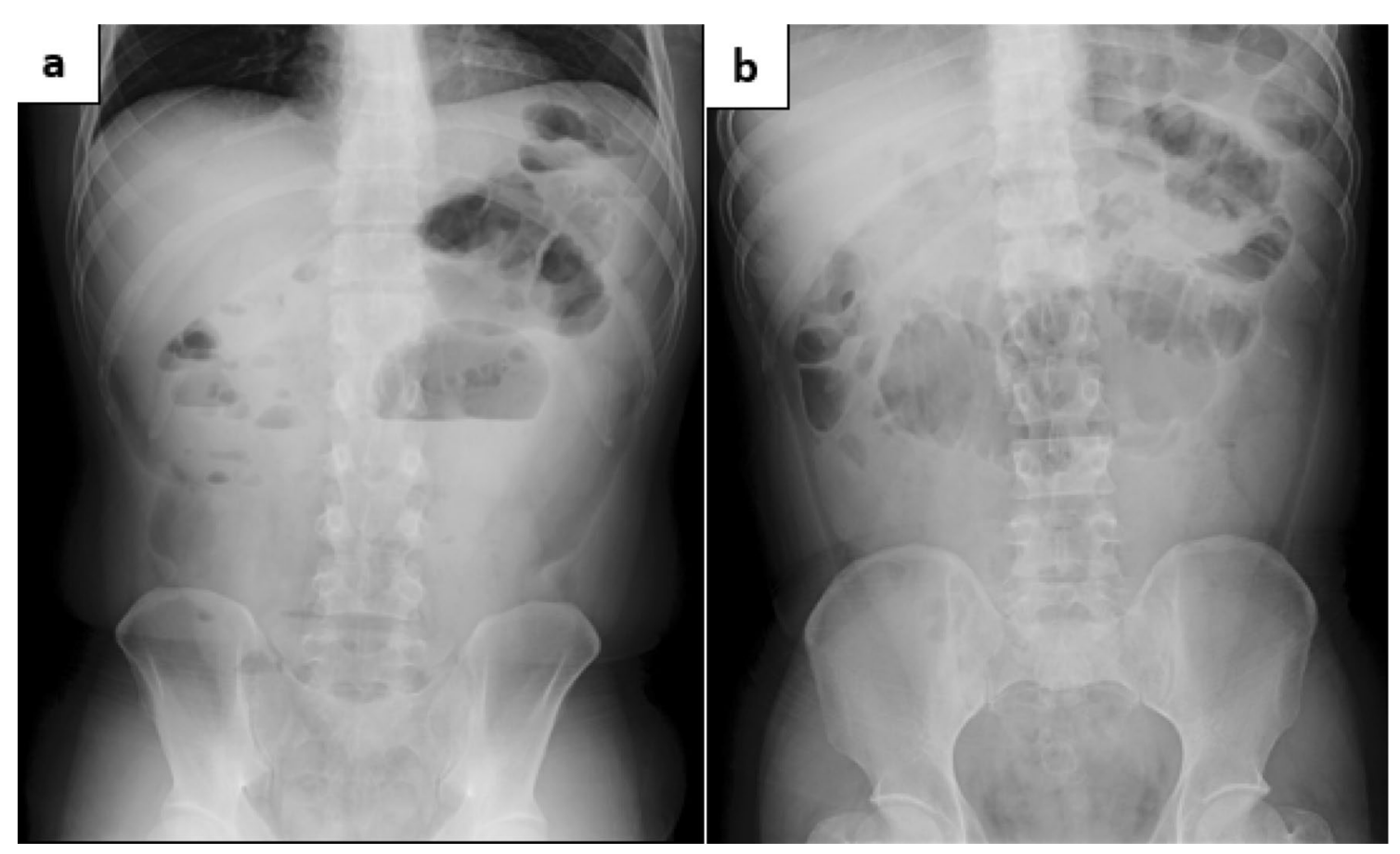

Fig. 2 Abdominal radiograph obtained in December 2017. a Standing position. b Decubitus position 

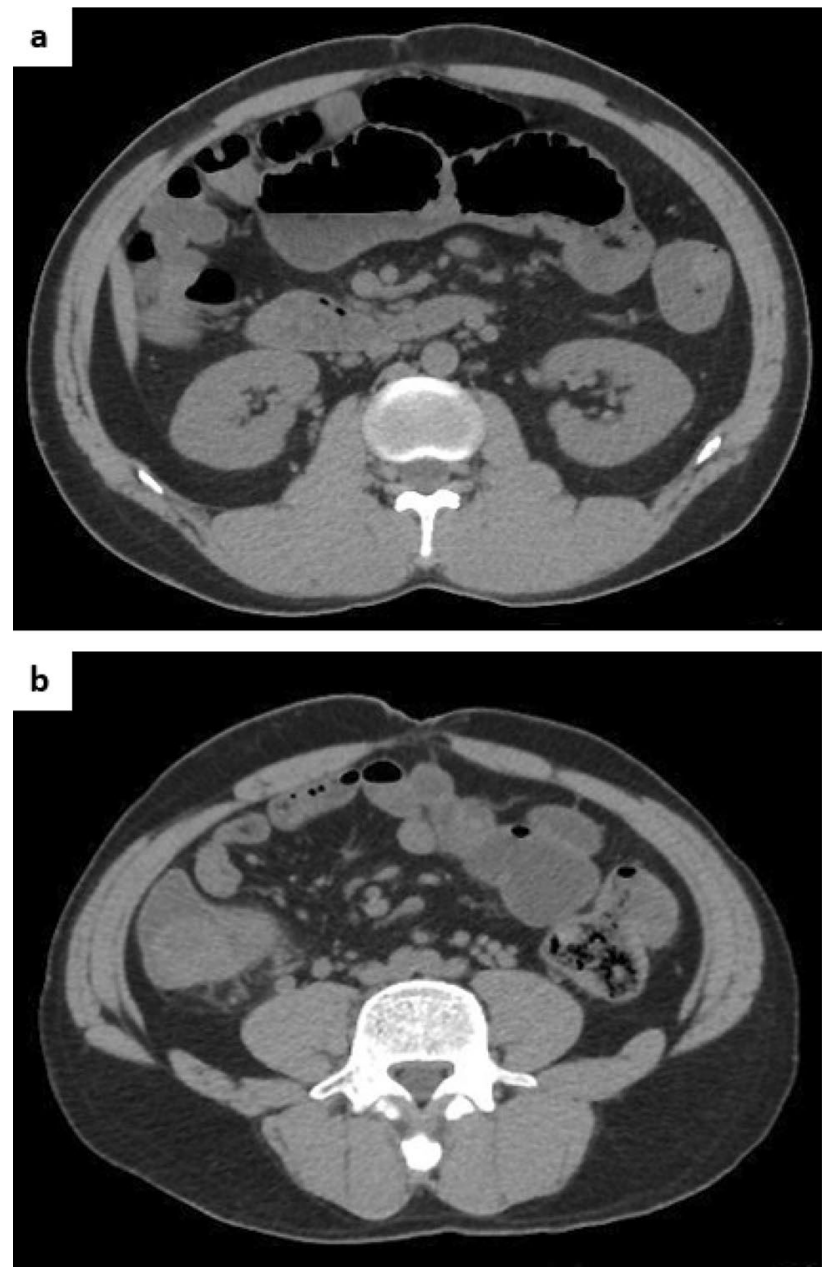

Fig. 3 Abdominal plain computed tomography performed in December 2017. a Discontinuous dilation in the small and large intestine. b Wall thickening of the ascending colon from the cecum near the ileocecal region

gastrointestinal endoscopic examination (Fig. 4) and found a protruding lesion with a $35 \mathrm{~mm}$ large, uneven nodule located in the cecum that was not detected in February 2017. The mouth side of the lesion had an expanding appearance, and the appendicular lesion was in contact with the appendicular opening. The surface of the nodule was slightly uneven with a villous change between the elevations (Fig. 4a-c). No obvious irregular blood vessel pattern was observed on narrow-band imaging (Fig. 4c, d). The biopsy result of the ileocecal lesion from the portion between the elevations revealed a high-grade tubulovillous adenoma, while that from the anal side revealed carcinoma of tub 1 and tub 2. We retrospectively examined the CT images from 2015 and noted that the ileocecal portion (Fig. 5) was normal; however, in February 2017 (Fig. 6a, b), CT suggested an enlarged appendix in the portion suspected to be the distal ileum.
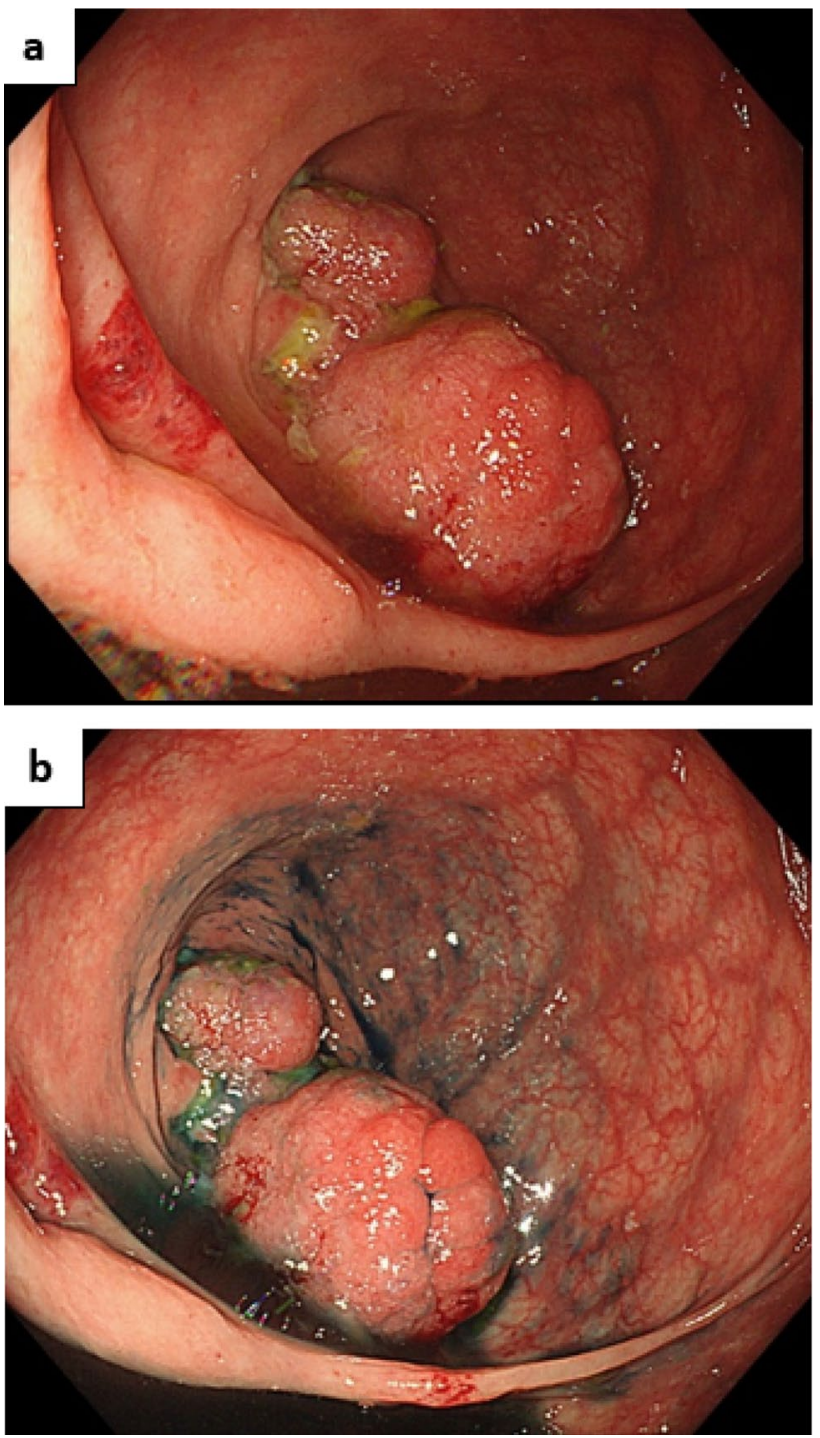

Fig. 4 Lower gastrointestinal endoscopy performed in December 2017. a Standard image. b Image with indigo carmine spray. c Narrow-band imaging (NBI) of the appendiceal lesion. d NBI of the anal side of the lesion

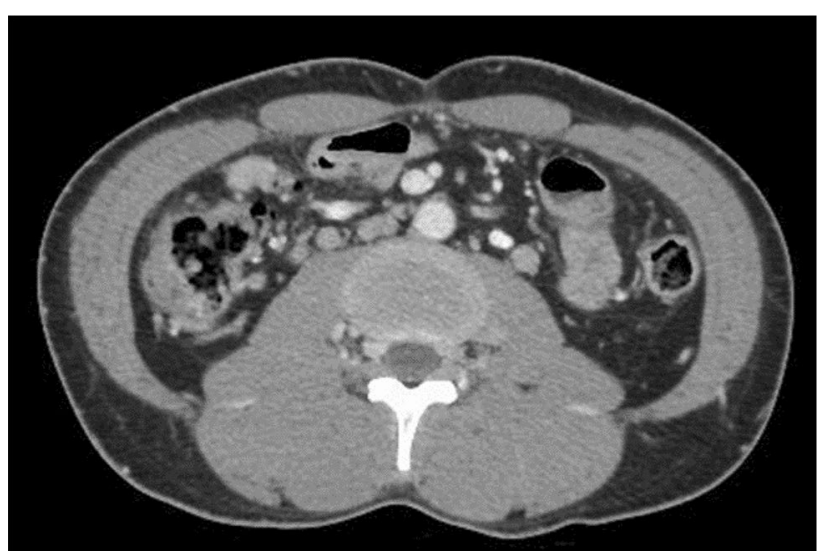

Fig. 5 Abdominal contrast computed tomography performed in 2015 



Fig. 6 Abdominal contrast computed tomography performed in February 2017. a, b An enlarged appendix is shown

\section{Final diagnosis}

The final pathological diagnosis of the main lesion was cecal carcinoma type 1 , tub $1>$ por $1>$ tub 2 , f stage IIIc (pT3pN2bM0) (TNM classification, 8th edition).

\section{Treatment}

From the day of hospitalization in December 2017, treatment with antibiotics was started for infectious enterocolitis, and the patient's diarrhea improved on the second day of hospitalization.

\section{Outcome and follow-up}

In March 2018, ileocecal resection and D3 dissection were performed. The pathological findings of the resected specimen (Fig. 7) and the appendicular lesion nodule (Fig. 4a, b) showed dendritic increase in the muscularis mucosa and hyperplasia of ducts, indicating a Peutz-Jeghers-type polyp (Fig. 7d). The appendicular lesion and that on the anal side were well-differentiated and poorly differentiated adenocarcinomas (Fig. 7e), respectively. Although there was no apparent tissue continuity between the Peutz-Jeghers-type polyps and the adenocarcinomas, some tubulovillous adenoma components were found in contact with the carcinoma. In addition, intussusception to the appendix opening and appendix was observed in the deep layer of the same plane, and Peutz-Jeghers-type polyp-like change was observed in the appendix mucosa (Fig. 7g).

After the third course of capecitabine plus oxaliplatin therapy, no clear sign of recurrence was noted on CT. Recurrence was evaluated based on capsule endoscopy, upper and lower gastrointestinal endoscopic examination, and contrastenhanced CT.

\section{Discussion}

PJS is an autosomal dominant disease characterized by hamartomatous polyposis occurring in all gastrointestinal tract regions, other than the esophagus, and manifests as pigmented spots on the lips, oral mucosa, and limbs [1]. The causative gene for PJS has been identified as the tumor suppressor gene $S T K 11 / L K B 1$ [2-4]. The frequencies of occurrence of Peutz-Jeghers hamartomas are $48.0-56.7 \%$ in the stomach, $13.8 \%$ in the duodenum, 56.9-73.9\% in the small intestine, and 48.8-65.8\% in the large intestine, and carcinogenesis has reportedly been seen in approximately $3 \%$ of cases [5]. Patients with PJS have a high potential to develop malignant tumors of the gastrointestinal tract, breast, pancreas, genital organs, and lungs.

There are various theories regarding the carcinogenic pathway underlying Peutz-Jeghers-type polyps including adenomas occurring in Peutz-Jeghers-type polyps, Peutz-Jeghers-type polyps themselves evolving to be malignant, adenomas existing independently from Peutz-Jegherstype polyps, and tumors arising in normal mucous membranes of polyps other than Peutz-Jeghers-type polyps [6, 7]. In the present case, adenoma and carcinoma developed concomitantly with the main lesion, and we speculate that a gene mutation had occurred based on the adenoma-carcinoma sequence theory [5].

In the present case, tumorous lesions were not found in the ileocecal region during the lower gastrointestinal endoscopy examination in February 2017, but carcinoma was found in the endoscopy examination in December of the same year. In the specimen resected in March of the next year, carcinoma invading the subserosal layer was observed. If the carcinoma had developed from the mucosa of the ileocecal area and followed the adenoma-carcinoma 
sequence theory, it seemed unlikely that it could have grown in the short period of approximately 1 year. Moreover, in February 2017, the CT examination showed enlargement of the appendix, suggesting the presence of a tumor in the appendix. Thus, it was speculated that appendix intussusception was present in December 2017; however, since the tumor was hidden in the appendix, it could not be found by lower endoscopy.

Appendix intussusception is a relatively rare disease, and clinical symptoms of abdominal pain and bloody stools are found in approximately half of the cases [8]. Anatomical factors of the appendix and abnormal peristaltic movements are considered to cause its onset [9], and there have been previous reports of PJS manifesting in the appendix [6]. Appendicular intussusception is diagnosed by abdominal ultrasonography, contrast-enhanced enema examination, lower digestive tract endoscopy, and abdominal CT examination; however, preoperative diagnosis is difficult, and many patients are diagnosed by a postoperative pathological examination.

Appendicular lesions of PJS have been reported in nine cases, including our case, until February 2019 based on a PubMed search using the following keyword combinations: "appendix," "Peutz," and "Jeghers" [6-8, 10-14]. Among them, there were four cases each of malignant tumor and appendix intussusception (Table 1). In addition, in six of the nine cases, the lesions were detected during surgery or diagnosed based on examination of the resected specimen after surgery. It has been also reported that the preoperative diagnosis of appendiceal cancer is difficult without an imaging modality, such as CT and abdominal ultrasonography [15]. However, in open surgery for conditions such as intussusception in patients with PJS, prophylactic appendectomy can prevent appendicular intussusception and tumorigenesis.

Recently, Beggs et al. [16] and van Lier et al. [17] conducted surveillance for patients with malignant tumors associated with PJS and proposed algorithms (Table 2); however, no consensus has been reached regarding the PJS surveillance methods and enforcement intervals [18]. Moreover, the proposed surveillance algorithms do not incorporate an imaging modality for organs other than the gastrointestinal tract, such as the appendix. On the basis of the findings in this case, we believe that imaging techniques, such as CT, abdominal ultrasonography, and positron emission tomography, are essential to evaluate the appendix.

In this case, the small intestine was observed using a capsule endoscope, and then polypectomy was performed. Although double-balloon endoscopy is also a useful option for exploration of the small intestine, Ohmiya et al. [19] reported that $90 \%$ of patients with a history of less than one laparotomy completed $90 \%$ of all small bowel examinations, and for those with a history of laparotomy, they reported a reduction to $27 \%$. Therefore, it is necessary to refer to the history of laparotomy as a means for examining the small intestine, and in this case, we considered that the capsule endoscope was an effective means.

On the basis of our findings, we think that there is a possibility to prevent appendicular tumorigenesis by performing prophylactic appendectomy during follow-up for PJS. 


4Fig.7 Pathological examination of the resected specimen. a Fixed sample. b, c Peutz-Jeghers-type polyp (blue), adenoma(green), and carcinoma (pink). d Peutz-Jeghers-type polyp. e Carcinoma (tub $1+$ tub 2). f Adenoma (left side) + carcinoma (right side). $\mathbf{g}$ The orifice and stack-like folding of the appendix

Table 1 Cause and frequency of appendiceal lesion in the literature

\begin{tabular}{llllllc}
\hline Author & Year & Age & Complaint & Mallignancy & $\begin{array}{l}\text { Appendix intus- } \\
\text { susception }\end{array}$ & Chance for discovery \\
\hline Chang [6] & 2014 & 50 & Right lower abdominal pain & - & + & During surgery \\
Miyahara [7] & 1995 & 40 & Anemia & + & + & Contrast enema \\
Moirangthem [8] & 2001 & 15 & Lower gastrointestinal bleeding & - & - & During surgery \\
Yoshikawa [10] & 1998 & 70 & Asymptomatic & + & + & During surgery \\
Skrovina [11] & 2007 & 44 & Right abdominal pain & - & - & During surgery \\
Iida [12] & 2008 & 78 & Right lower abdominal pain & - & - & CT \\
Nozoe [13] & 2013 & 65 & Unknown & - & - & Resected specimen \\
Hofmann [14] & 2014 & 21 & Nausea and abdominal pain & + & During surgery \\
Self-experience & 2018 & 39 & Vomiting and diarrhea & + & CT, colonoscopy \\
\hline
\end{tabular}

$C T$ computed tomography

Table 2 Surveillance of PeutzJeghers syndrome

\begin{tabular}{|c|c|}
\hline Article & Surveillance algorithm \\
\hline Begg [16] & $\begin{array}{l}\text { Upper and lower digestive tract endoscopy at } 8 \text { years } \\
\text { Polyps detected: every } 3 \text { years until } 50 \text { years } \\
\text { Polyps not detected: re-examination at } 18 \text { years, after that every } \\
3 \text { years until } 50 \text { years } \\
\text { Lower digestive tract endoscopy: every } 1-2 \text { years after } 50 \text { years } \\
\text { Video capsule endoscopy: every } 3 \text { years after } 8 \text { years } \\
\text { Testicular ultrasonography: every year until } 12 \text { years } \\
\text { Cervical cytology: every } 3 \text { years until } 25 \text { years } \\
\text { Breast MRI: every year after } 25 \text { until } 50 \text { years } \\
\text { Mammography: every year after } 50 \text { years }\end{array}$ \\
\hline Van Lier [17] & $\begin{array}{l}\text { Consultation and Hb level test: every year after } 10 \text { years } \\
\text { Upper digestive tract endoscopy: every } 2-5 \text { years after } 20 \text { years } \\
\text { Lower digestive tract endoscopy: every } 2-5 \text { years after } 25-30 \text { years } \\
\text { Video capsule endoscopy: every } 2-3 \text { years after } 10 \text { years } \\
\text { MRCP, EUS: every } 2-5 \text { years after } 30 \text { years } \\
\text { Cervical cytology: every year until } 25-30 \text { years } \\
\text { Transvaginal ultrasonography: every year after } 25-30 \text { years } \\
\text { CA-125 level test: every year after } 25-30 \text { years } \\
\text { Breast MRI: every year after } 25 \text { years } \\
\text { Mammography: every year after } 30 \text { years }\end{array}$ \\
\hline
\end{tabular}

MRCP magnetic resonance cholangiopancreatography, EUS endoscopic ultrasonography, $C A-125$ cancer Antigen $125, H b$ hemoglobin 
Acknowledgments We thank the following individuals for their assistance in the present study: Dr. Kenta Hashigami, Dr. Hiroyuki Kobayashi, Dr. Yuichi Nozawa, Dr. Toshiharu Takahashi, Dr. Yoshiki Mizukami, Dr. Kumiko Shirahata, Dr. Shinji Okaniwa, Dr. Kenji Sano, and Dr. Yoshiyuki Nakamura.

Author contributions All authors contributed to the study conception and design. The first draft of the manuscript was written by Kazuhiro Kurihara, and all authors commented on previous versions of the manuscript.

\section{Compliance with ethical standards}

Conflict of interest The authors declare that they have no conflict of interest.

Informed consent This case complies with the ethical standards of the human experimentation committee responsible and is in accordance with the World Medical Association and the Declaration of Helsinki. The authors followed the protocols of their institutions to access the patient data. The family of the patient authorized the submission and publication of this work.

Open Access This article is licensed under a Creative Commons Attribution 4.0 International License, which permits use, sharing, adaptation, distribution and reproduction in any medium or format, as long as you give appropriate credit to the original author(s) and the source, provide a link to the Creative Commons licence, and indicate if changes were made. The images or other third party material in this article are included in the article's Creative Commons licence, unless indicated otherwise in a credit line to the material. If material is not included in the article's Creative Commons licence and your intended use is not permitted by statutory regulation or exceeds the permitted use, you will need to obtain permission directly from the copyright holder. To view a copy of this licence, visit http://creativecommons.org/licenses/by/4.0/.

\section{References}

1. Hizawa K, Iida M, Matsumoto T, et al. Neoplastic transformation arising in Peutz-Jeghers polyposis. Dis Colon Rectum. 1993;36:953-7.

2. Hemminki A, Tomlinson I, Markie D, et al. Localization of a susceptibility locus for Peutz-Jeghers syndrome to 19p using comparative genomic hybridization and targeted linkage analysis. Nat Genet. 1997;15:87-90.

3. Hemminki A, Markie D, Tomlinson I, et al. A serine/threonine kinase gene defective in Peutz-Jeghers syndrome. Nature. 1998;391:184-7.
4. Jenne DE, Reimann H, Nezu J, et al. Peutz-Jeghers syndrome is caused by mutations in a novel serine threonine kinase. Nat Genet. 1998;18:38-433.

5. Cho KR, Vogelstein B. Genetic alterations in the adenoma-carcinoma sequence. Cancer. 1992;70:1727-31.

6. Choi CI, Kim DH, Jeon TY, et al. Solitary Peutz-Jeghers-type appendiceal hamartomatous polyp growing into the terminal ileum. World J Gastroenterol. 2014;20:4822-6.

7. Miyahara M, Saito T, Etoh K, et al. Appendiceal intussusception due to an appendiceal malignant polyp-An association in a patient with Peutz-Jeghers syndrome: report of a case. Surg Today. 1995;25:834-7.

8. Moirangthem GS, Nepram SS, Debnath K, et al. Peutz-Jeghers syndrome involving appendix. Int Surg. 2001;86:252-3.

9. Paul GJ, Ferraro LR. Intussusception of the appendix. NY State J Med. 1967;67:2625-9.

10. Yoshikawa A, Kuramoto S, Mimura T, et al. Peutz-Jeghers syndrome manifesting complete intussusception of the appendix and associated with a focal cancer of the duodenum and a cystadenocarcinoma of the pancreas: report of a case. Dis Colon Rectum. 1998;41:517-21.

11. Skrovina M, Czudek S, Bartos J, et al. The Peutz-Jeghers syndrome-a case review. Rozhl Chir. 2007;86:24-6.

12. Iida $\mathrm{H}$, Inamori $\mathrm{M}$, Sekino $\mathrm{Y}$, et al. Acute appendicitis associated with Peutz-Jeghers-type hamartoma of the appendix. Dig Dis Sci. 2008;53:2832-3.

13. Nozoe T, Mori E, Iguchi T, et al. Pedunculated hamartomatous polyp of the appendix: report of a case. Surg Today. 2013;43:191-3.

14. Hofmann S, Barth TF, Kornmann M, et al. Appendix carcinoid associated with the Peutz-Jeghers syndrome. Int J Surg Case Rep. 2014;5:964-7.

15. Yatabe $\mathrm{S}$, Nakajima $\mathrm{S}$, Hanyu $\mathrm{K}$, et al. A case of early primary adenocarcinoma of the appendix diagnosed preoperatively by colon fiberscopy. Jpn J gastroenterol surg. 2013;46(7):530-7.

16. Beggs AD, Latchford AR, Vasen HF, et al. Peutz-Jeghers syndrome: a systematic review and recommendations for management. Gut. 2010;59:975-86.

17. Van Lier MG, Wagner A, Mathus-Vliegen EM, et al. High cancer risk in Peutz-Jeghers syndrome: a systematic review and surveillance recommendations. Am J Gastroenterol. 2010;105:1258-64.

18. Giardiello FM, Trimbath JD. Peutz-Jeghers syndrome and management recommendations. Clin Gastroenterol Hepatol. 2006;4:408-15.

19. Ohmiya N, Nakamura M, Takenaka $H$, et al. Management of small-bowel polyps in Peutz-Jeghers syndrome by using enteroclysis, double-balloon enteroscopy, and videocapsule endoscopy. Gastrointest Endosc. 2010;72:1209-16.

Publisher's Note Springer Nature remains neutral with regard to jurisdictional claims in published maps and institutional affiliations. 